\title{
The Formation of Fungal Sporopollenin in the Zygospore Wall of Mucor mucedo: a Role for the Sexual Carotenogenesis in the Mucorales
}

\author{
By G. W. GOODAY \\ Department of Biochemistry, University of Aberdeen, Aberdeen, AB9 I $A S$ \\ AND P. FAWCETT, D. GREEN AND G. SHAW \\ Department of Chemistry, University of Bradford, Bradford, $B D_{7}$ I $D P$
}

(Received 24 July 1972)

SUMMARY

Exhaustive alkali and acid extraction of Mucor mucedo zygospores leaves a residue that is chemically very similar to higher plant and synthetic sporopollenins. This Mucor sporopollenin is probably a component of the outer part of the zygospore wall. The incorporation of radioactive acetate, mevalonate and $\beta$-carotene suggests that it is biosynthesized by an oxidative polymerization of $\beta$-carotene. Thus sporopollenin formation is probably a role for the increased carotenogenesis observed during sexual reproduction of many members of the Mucorales.

\section{INTRODUCTION}

There have been many reports of increases in carotene content during sexual reproduction in members of the Mucorales (reviewed by Hesseltine, I96I ; Burnett, I965). These increases are most noticeable in the mycelium directly involved in the sexual reactions, and Hocking (1965) has shown that in Phycomyces blakesleeanus the stimulation of $\beta$-carotene accumulation in mated cultures is localized in the gametangia.

Until now, no direct function for this increased carotenogenesis has been apparent. The recent finding that the trisporic acids, sex hormones in the Mucorales, are oxidation products of $\beta$-carotene (Austin, Bu'Lock \& Gooday, 1969; Austin, Bu'Lock \& Winstanley, 1969; Austin, Bu'Lock \& Drake, 1970) is an example of direct involvement of carotene in the sexual processes in these fungi. However, the formation of trisporic acids cannot be a primary function of the observed increases in carotene content, because in Mucor mucedo (Gooday, 1968a) and Blakeslea trispora (Thomas \& Goodwin, 1967; van den Ende, 1968; Sutter \& Rafelson, I968) increases of the same order can be obtained by adding trisporic acids to unmated cultures of the fungi, and so must be a consequence and not a prerequisite of hormone production.

The report that sporopollenins, structural components of pollen exine, are derived by oxidative polymerization of carotenoids or carotenoid esters (Brooks \& Shaw, I $968 a, b$, I97I : Shaw, 1970, I97I) has led us to investigate whether a similar mechanism could be operating in the Mucorales to give rise to a component of the zygospore wall. Thus the chemistry of the zygospore wall of $M$. mucedo and the incorporation into it of possible precursors have been studied. The zygospores of a related fungus, Rhizopus sexualis, that has been reported not to accumulate carotenoids (Hocking, 1963), have also been analysed. 


\section{METHODS}

Cultures. The two strains of Mucor mucedo Brefeld, z43 (-) and z46(+), were those used by Gooday (1968 $a, b$ ). Rhizopus sexualis (Smith) Callen (strain $\mathrm{z7} b$ in the culture collection in the Botany Department, University of Bristol) was kindly provided by Professor L. E. Hawker, and Blakeslea trispora Thaxter [NRRL 2895 (+) and NRRL 2896 (-)] was kindly provided by Dr J. D. Bu'Lock, University of Manchester.

Radioactive chemicals. Sodium $\left[\mathrm{U}-{ }^{14} \mathrm{C}\right]$ acetate and $\mathrm{D}, \mathrm{L}-\left[2-{ }^{14} \mathrm{C}\right]$ mevalonic acid were supplied by the Radiochemical Centre, Amersham, Buckinghamshire. $\left[15, \mathrm{I} 5^{\prime}-{ }^{3} \mathrm{H}\right] \beta$-Carotene was generously supplied by Roche Products Ltd, Welwyn Garden City, Hertfordshire. $\left[\mathrm{G}-{ }^{14} \mathrm{C}\right] \beta-$ Carotene was prepared biologically by a modification of the technique of Anderson, Norgard \& Porter (I960). Mated cultures of Blakeslea trispora were incubated at $28{ }^{\circ} \mathrm{C}$ in a culture medium consisting of (g/l of water): glucose, $40 ; \mathrm{MgSO}_{4} .7 \mathrm{H}_{2} \mathrm{O}, 0.25 ; \mathrm{L}$-asparagine, 2 ; malt extract, $20 ; \mathrm{KH}_{2} \mathrm{PO}_{4}, 0.5$; adjusted to $\mathrm{pH} 6$. After $30 \mathrm{~h}$ growth, $300 \mu \mathrm{Ci}$ of sodium $\left[\mathrm{U}^{14} \mathrm{C}\right]-$ acetate was added from a sterile syringe, and $48 \mathrm{~h}$ later the culture medium was filtered off and the mycelium pressed dry. The mycelium was macerated in a Waring blender and thoroughly extracted with light petroleum (b.p. 40 to $60^{\circ} \mathrm{C}$ ), with non-radioactive $\beta$-carotene added as a carrier. The petroleum solution was extracted with water and saponified by refluxing with $10 \%$ ethanolic potassium hydroxide for $30 \mathrm{~min}$. The solution was diluted with water and non-saponified material extracted with more light petroleum. The extract (dried with $\mathrm{Na}_{2} \mathrm{SO}_{4}$ ) was chromatographed on a magnesia-super cel column (I : I by weight). $\beta$-Carotene was separated from other carotenes and polyenes by elution with a $10 \%$ solution of acetone in petroleum ether. This $\beta$-carotene fraction was rechromatographed twice on an activated alumina column and finally $\left[{ }^{14} \mathrm{C}\right] \beta$-carotene was crystallized to constant specific activity.

Zygospore production. Mated cultures of Mucor mucedo were grown from dense inocula of equal numbers of $(+)$ and $(-)$ sporangiospores (Gooday, $1968 \mathrm{~b}$ ), at $20{ }^{\circ} \mathrm{C}$ on a medium of $2 \%$ malt extract, $2 \%$ glucose, $2 \%$ agar, $0.5 \%$ peptone, using $25 \mathrm{ml}$ medium in each $9 \mathrm{~cm}$ Petri dish. Zygospores were collected 2 weeks after inoculation by scraping the surface of the cultures with a flat-edged scalpel, and were then dried in a vacuum desiccator over phosphorus pentoxide.

The radioactive substrates were added to mated cultures of Mucor mucedo $24 \mathrm{~h}$ after inoculation, and the zygospores harvested after a further Io days of growth. Acetate and mevalonate were added under sterile conditions in aqueous solution by means of a 'Swinnex' filter (Millipore type GSoI 3). The radioactive $\beta$-carotene was dissolved in light petroleum (b.p. 40 to $60^{\circ} \mathrm{C}$ ): acetone (4:I) and this solution was added to an autoclaved mixture of equal volumes of vegetable oil ('Mazola' corn oil) and $4 \%$ (v/v) Tween 80 surfactant. This was then rapidly stirred in a stream of nitrogen until an emulsion was obtained and the volatile solvents had evaporated. This emulsion was added to the mycelium with a sterile syringe and was uniformly distributed over the culture with a glass rod. About $0.2 \mathrm{ml}$ containing approximately $2 \mathrm{mg}\left[{ }^{14} \mathrm{C}\right] \beta$-carotene or $0.5 \mathrm{mg}\left[{ }^{3} \mathrm{H}\right] \beta$-carotene was spread on each Petri dish.

Identification of sporopollenin. The acid- and alkali-resistant material from the Mucor mucedo zygospore walls has been characterized by the methods used for the sporopollenin from pollen samples as described by Brooks \& Shaw (1968 $a, b, 1970,1971)$. These methods entail elemental analysis, determining resistance to acetolysis, infrared spectrometry, pyrolysis gas chromatography, and examination of the products following potash fusion and ozonolysis. An important additional method has been the comparison of the natural product with synthetic products produced by oxidative polymerization of carotenoids in the presence of 
an organic catalyst (Shaw, 1970, I971). More recent work has used combined gas-liquid chromatography (g.l.c.)-mass spectrometry to characterize ozonolysis products, and capillary-column g.l.c. to study g.l.c.-mass pyrolysis products. Full details of these techniques will be published elsewhere.

Assay of sporopollenin. Weighed amounts of the dry zygospores were extracted successively with ether and methanol and then refluxed for $6 \mathrm{~h}$ with $6 \%$ methanolic potassium hydroxide. The solution was acidified with $\mathrm{IO} \mathrm{N}-\mathrm{HCl}$ and the spores were collected and thoroughly washed with hot water, hot methanol, acetone and ether. The residue was suspended in $80 \%$ orthophosphoric acid at $50{ }^{\circ} \mathrm{C}$ for 10 days, then collected and washed with hot dilute $\mathrm{HCl}$, hot water, hot methanol, acetone and ether. The resulting sporopollenin was dried in vacuo at $50{ }^{\circ} \mathrm{C}$ for $6 \mathrm{~h}$ over phosphorus pentoxide.

To reduce possibilities of contamination by adsorption of labelled materials, successive solvent extractions were carried out until the extracts were free from radioactivity. Table 3 gives the counts obtained in the different extracts. The ${ }^{14} \mathrm{C}$ and tritium contents of the sporopollenins were determined by the modified combustion technique (Buyske et al. I96I). A sample of the material was weighed, bound with pure sucrose and burnt in an atmosphere of oxygen. Liberated ${ }^{14} \mathrm{CO}_{2}$ was absorbed in a $22 \%$ solution of ethanolamine in methanol. Samples were taken and counted in $10 \mathrm{ml}$ of NE 220 scintillator. The tritium content was separately determined by condensing the liberated ${ }^{3} \mathrm{H}_{2} \mathrm{O}$ and absorbing it in a $10 \%$ solution of absolute alcohol in toluene scintillator. A Io $\mathrm{ml}$ sample was taken for counting.

All activity determinations were carried out with a Packard Tricarb scintillation spectrometer and quenching corrections were applied by the channels ratio method (Bush, 1963). Where sufficient material was available results are the mean of duplicate combustions.

After the specific activity of the sporopollenins had been determined, remaining material when available was retreated with $80 \%$ orthophosphoric acid for io days at $50{ }^{\circ} \mathrm{C}$, followed by thorough washing with water, methanol, acetone and ether. The specific activities of the samples were again determined. There was normally little change except in the material when $\left[{ }^{3} \mathrm{H}\right] \beta$-carotene was the precursor, when the increase in specific activity correlated with the weight loss during retreatment. However, the samples still contained substantial but varying amounts of ash (rich in phosphate) and smaller amounts of resistant phosphorylated polysaccharide residues. These could be removed with difficulty by further treatment with acid and alkali without loss of radioactivity. Ozonization of the sporopollenin preparations removed all the radioactivity to leave a residue of remnants of the ash.

Experiments have shown that hydrogen atoms in sporopollenins are reluctant to exchange with tritiated protons even in the presence of protonating catalysts ( $G$. Shaw and colleagues, unpublished work) and so direct exchange of ${ }^{3} \mathrm{H}_{1}$ between $\left[{ }^{3} \mathrm{H}\right] \beta$-carotene and sporopollenin is unlikely in the present work.

\section{RESULTS AND DISCUSSION}

\section{Identity of the sporopollenin}

By all criteria used so far the material prepared from the Mucor zygospores is very similar to sporopollenins from many different pollens and is virtually identical to the polymer chemically synthesized by a catalysed oxidative polymerization of $\beta$-carotene, the major carotenoid of Mucor mucedo. All these materials survive the treatment with solvents and the subsequent alkali and acid extractions, and also survive acetolysis. Typical elemental compositions are given in Table I. Some of the other chemical data for these materials have been published previously: infrared spectral absorption bands; major peaks on pyrolysis gas 
Table I. Elemental composition of some sporopollenins

\begin{tabular}{ll}
\multicolumn{1}{c}{ Source } & Empirical formula* \\
Mucor mucedo sporopollenin & $\mathrm{C}_{90} \mathrm{H}_{130} \mathrm{O}_{33}$ \\
Polymer of $\beta$-carotene $\dagger$ & $\mathrm{C}_{90} \mathrm{H}_{130-132} \mathrm{O}_{27-32}$ \\
Lilium henryi sporopollenin & $\mathrm{C}_{90} \mathrm{H}_{142} \mathrm{O}_{36}$ \\
Polymer of $L$. henry $i$ carotenoids & $\mathrm{C}_{90} \mathrm{H}_{148} \mathrm{O}_{38}$ \\
$\quad$ and carotenoid esters $\dagger$ &
\end{tabular}

* Arbitrarily expressed in terms of $C_{90}$ units (see Shaw, 197I).

$\uparrow$ Prepared from carotenoids in solution in methylene dichloride in the presence of oxygen and with $\mathrm{BF}_{3}$ as catalyst. The elemental analysis varies with the conditions used, with the more dilute solutions of $\beta$-carotene giving material closer to the values from $M$. mucedo.

Table 2. Percentage composition of the major dicarboxylic acids produced by ozonolysis of sporopollenins*

\begin{tabular}{lcccc}
\multicolumn{1}{c}{ Source } & 3 & 4 & 5 & 6 \\
Mucor sporopollenin & $3 \cdot 8$ & $4 \cdot \mathrm{I}$ & $5 \cdot 4$ & $70 \cdot \mathrm{I}$ \\
Polymer of $\beta$-carotene $\dagger$ & $0 \cdot 8$ & $6 \cdot 0$ & $7 \cdot 9$ & $79 \cdot 2$ \\
Polymer of iso-zeaxanthin $\dagger$ & Trace & $3 \cdot 8$ & $3 \cdot 8$ & $77 \cdot 4$
\end{tabular}

* Estimated by g.l.c.-mass spectrometry as methyl esters.

$\dagger$ Prepared as for Table $\mathrm{I}$.

chromatograms; $m$ - and $p$-hydroxybenzoic acids as major phenolic acids following potash fusion (Shaw, I970, 197I; Brooks \& Shaw, 1971). Recent results from a combined gas chromatographic-mass spectral examination of dicarboxylic acids obtained by ozonolysis show that the products from the Mucor sporopollenin are very similar to those from the oxidative polymers of $\beta$-carotene and of iso-zeaxanthin (Table 2). Iso-zeaxanthin is one of the earliest oxidation products during treatment of $\beta$-carotene with oxygen and boron trifluoride (Petracek \& Zechmeister, 1956) and so could also be an intermediate in the biosynthesis of sporopollenin from $\beta$-carotene. Recent capillary-column pyrolysis gas chromatograms have confirmed the earlier evidence that the pyrolysis products from the Mucor sporopollenin and the $\beta$-carotene polymer are very similar. These products are currently being further characterized by means of a coupled mass spectrometer and the results will be published elsewhere.

Our findings clearly endorse the suggestion that the term 'sporopollenin' should no longer be confined to higher plant products (Brooks \& Shaw, 1970; Shaw, 1971 ; and discussion by I. Faegri in Shaw, 1971).

\section{Localization of the sporopollenin}

The sporopollenin preparations are about 3 to $4 \%$ of the dry weight of the original zygospore collections, but when allowance is made for the contaminating ash and residual phosphorylated polysaccharides the sporopollenin content of different preparations of the zygospores varies between I and $3 \%$. Pollen grains from different species show a wide variation in sporopollenin content, but these figures may be compared with that of $5.3 \%$ in Lilium henryi pollen (Shaw, I97I).

The early stages of the extraction procedure (chiefly the treatment with methanolic alkali) remove about $90 \%$ of the dry weight of the zygospores. This loss is probably accounted for by the cytoplasm and some wall components, such as the black pigment. The residue consists of the shells of the zygospores, with the outer warty ornamented thickenings 
Table 3. Incorporation of radioactive precursors into sporopollenin in Mucor mucedo zygospores

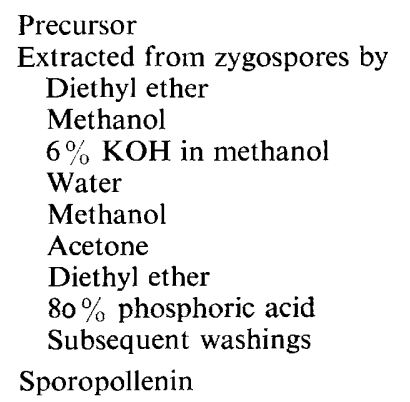

\section{Precursor \\ Sporopollenin \\ Re-extracted sporopollenin \\ Sporopollenin corrected for ash content}

\begin{tabular}{|c|c|c|c|}
\hline \multicolumn{4}{|c|}{ Radioactive precursor } \\
\hline $\begin{array}{c}{\left[\mathrm{U}-{ }^{14} \mathrm{C}\right]-} \\
\text { acetate }\end{array}$ & $\begin{array}{l}{\left[2{ }^{14} \mathrm{C}\right]-} \\
\text { mevalonate }\end{array}$ & $\underset{\beta \text {-carotene }}{\left[\mathrm{G}^{14} \mathrm{C}\right]-}$ & $\begin{array}{c}{\left[15,15^{\prime}-{ }^{3} \mathrm{H}\right]} \\
\beta \text {-carotene }\end{array}$ \\
\hline \multicolumn{4}{|c|}{ Total radioactivity (d.p.m.) } \\
\hline $192.5 \times 10^{6}$ & $19 \cdot 9 \times 10^{6}$ & $3.04 \times 10^{6}$ & $3330 \times 10^{6}$ \\
\hline $17.7 \times 10^{6}$ & $0.6 \times 10^{6}$ & $13.9 \times 10^{3}$ & $8.5 \times 10^{6}$ \\
\hline $14.0 \times 10^{6}$ & $3.8 \times 10^{6}$ & $72 \cdot 4 \times 10^{3}$ & $60.0 \times 10^{3}$ \\
\hline $10.1 \times 10^{6}$ & $0.1 \times 10^{6}$ & $0.8 \times 10^{3}$ & $5.0 \times 10^{3}$ \\
\hline $2.4 \times 10^{6}$ & $31.0 \times 10^{3}$ & 0 & 0 \\
\hline $56.3 \times 10^{3}$ & $2.6 \times 10^{3}$ & 0 & o \\
\hline $3.0 \times 10^{3}$ & $0.5 \times 10^{3}$ & 0 & 0 \\
\hline 0 & 0 & 0 & 0 \\
\hline $\begin{array}{c}\text { N.D. } \\
0\end{array}$ & $\begin{array}{c}\text { N.D. } \\
0\end{array}$ & $\begin{array}{c}\text { N.D. } \\
0\end{array}$ & $\begin{array}{c}\text { N.D. } \\
0\end{array}$ \\
\hline 48536 & 6128 & 828 & 205434 \\
\hline \multicolumn{4}{|c|}{ Specific activity (d.p.m. $\mathrm{mg}^{-1}$ ) } \\
\hline $4.69 \times 10^{6}$ & $3.99 \times 10^{6}$ & $0.118 \times 10^{6}$ & $355.2 \times 10^{6}$ \\
\hline 355 & 58 & 8 & 1713 \\
\hline 334 & 62 & N.D. & 3065 \\
\hline N.D. & N.D. & N.D. & 5066 \\
\hline
\end{tabular}

readily separating from the inner impermeable walls when pressed between a microscope slide and a coverslip. Earlier workers (references in Hawker \& Gooday, 1968) have described up to five layers in the wall, but Hawker \& Gooday (I968) and Hawker \& Beckett (197I) have re-examined this problem and have been able to clarify the structure and formation of the zygospore wall. Of the two major layers visible in the light microscope, the sporopollenin is probably in the outer warty layer because the inner impermeable elastic layer is readily soluble in strong acids. Treatment with phosphoric acid immediately causes this inner layer to swell and disperse, and then the outer thickenings slowly fall apart into the separate warts. Eventually the sporopollenin is left as an amorphous residue. There is little suggestion of anything like the coherent shells of sporopollenin obtained from pollen grains by the same treatment.

Other components of the zygospore wall have not been examined in detail, but histochemical staining of spores of Mucor mucedo and Rhizopus sexualis indicates that chitin is present in the inner impermeable layer and that chitin and chitosan - both characteristic wall components in the Mucorales (Bartnicki-Garcia, I968) - are present in the warty thickenings (G. W. Gooday, unpublished).

Vegetative mycelium and sporangiospores of Mucor mucedo and mycelium and zygospores of Rhizopus sexualis were completely solubilized by the extraction procedure, leaving no detectable sporopollenin. Zygospores of Blakeslea trispora have not yet been obtained in sufficient quantities in our cultures for full analysis but preliminary results indicate that they leave a residue after the phosphoric acid extraction which could be a sporopollenin. The failure to detect sporopollenin in $R$. sexualis zygospores correlates with the failure to detect carotene in this fungus (Hocking, 1963). However, it also requires comment as these zygospores appear very similar in structure and formation to those of $M$. mucedo. This suggests that the sporopollenin does not play an essential structural role in the zygospore wall. The 


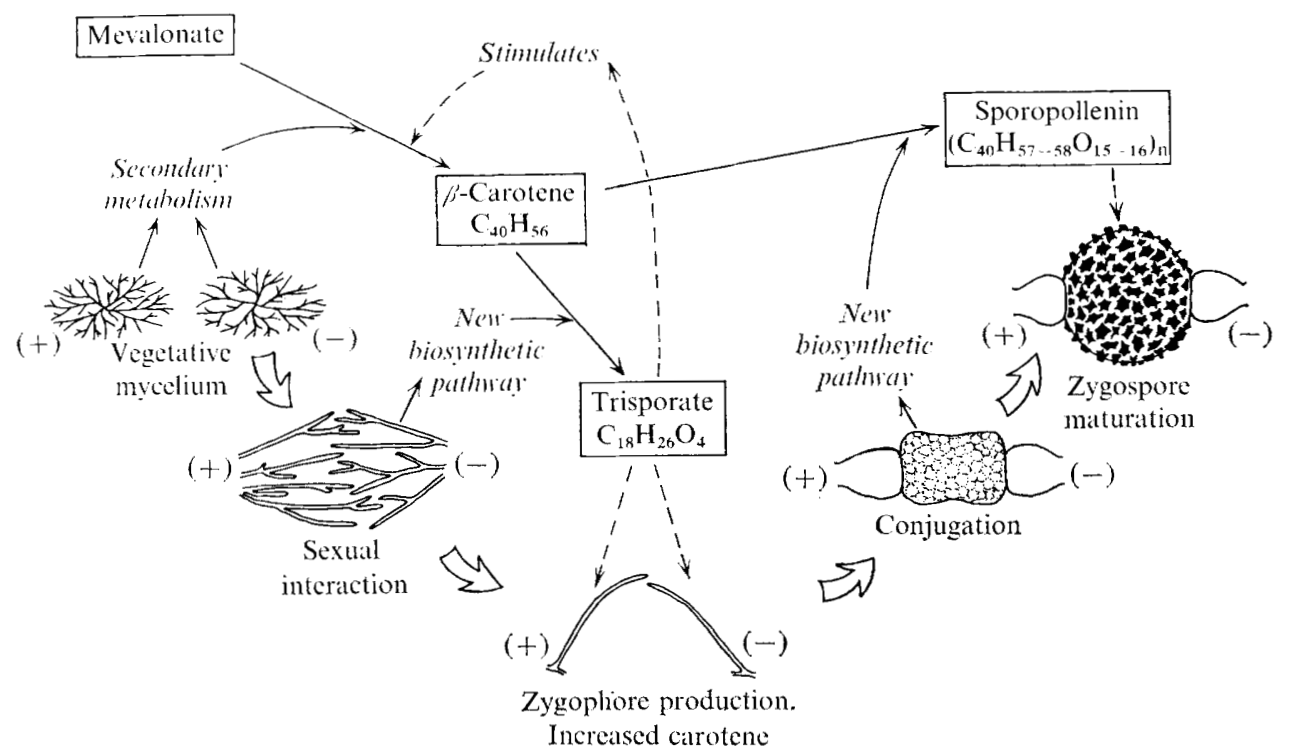

Fig. I. Proposed scheme of involvement of carotene in sexual reproduction in Mucor mucedo.

extreme resistance of sporopollenin to both chemical and biological degradation (Shaw, I97I) makes it more likely that its role is to give further protection to the zygospore.

\section{Incorporation of radioactive precursors}

Acetate, mevalonate and $\beta$-carotene have been incorporated into sporopollenin in the zygospores in our experiments (Table 3). Percentage incorporations have not been quoted as only the purest collections of zygospores were used, and those spores remaining entangled with vegetative hyphae were discarded.

The polymerization of $\beta$-carotene to give a component of the zygospore wall is clearly a major function of the observed increase in carotenogenesis during sexual reproduction in Mucor mucedo and probably in many other members of the Mucorales. Many earlier workers have described orange droplets accumulating in the suspensors and developing zygospores, but absent in the mature zygospores (Ling-Young, 1930, and references therein), yet only recently has it been realized that carotenoids can be polymerized in nature to give structural components (Brooks \& Shaw, I968a).

Fig. I illustrates the proposed scheme of metabolic involvement of carotene in sexual reproduction in Mucor mucedo. The formation of sporopollenin from carotene in the zygospores, but not in the vegetative mycelium or asexual spores, is a further example of the fate of some microbial secondary metabolites which are incorporated into structual components during spore formation (discussed by Bu'Lock, I96I, I967). The finding that carotenedeficient mutants of Phycomyces blakesleeanus give few or no zygospores when mated (R. P. Sutter \& R. DeHaven, personal communication) is further confirmation of the importance of carotene in zygospore formation in those species accumulating the pigment. 


\section{REFERENCES}

Anderson, D. G., Norgard, D. W. \& Porter, J. W. (1960). Incorporation of mevalonic acid-2-C ${ }^{14}$ and dimethylacrylic acid-3-C $\mathrm{C}^{\mathbf{4}}$ into carotenes. Archives of Biochemistry and Biophysics 88, 68-77.

Austin, D. J., Bu'Lock, J. D. \& Drake, D. (1970). The biosynthesis of trisporic acids from $\beta$-carotene via retinal and trisporol. Experientia 26, 348-349.

Ausirn, D. J., Bu'Lock, J. D. \& Gooday, G. W. (1969). Trisporic acids: Sexual hormones from Mucor mucedo and Blakeslea trispora. Nature, London 223, I I 78 -I 179.

Austin, D. J., Bu'Lock, J. D. \& Winstanley, D. J. ( I969). Trisporic acid biosynthesis and carotenogenesis in Blakeslea trispora. Biochemical Journal $113,34 P$.

Bartnicki-GarCIA, S. ( 1968). Cell wall chemistry, morphogenesis, and taxonomy of fungi. Annual Review of Microbiology 22, 87-108.

Brooks, J. \& SHAw, G. (I968a). Chemical structure of the exine of pollen walls and a new function for carotenoids in nature. Nature, London 219, 532-533.

Brooks, J. \& SHAw, G. (1968b). The post-tetrad ontogeny of the pollen wall and the chemical structure of the sporopollenin of Lilium henryi. Grana Palynologica 8, 227-234.

Brooks, J. \& S HAW, G. (1970). Relationship of kerogen and sporopollenin - a reply. Nature, London 227, $195-196$.

Brooks, J. \& SHAW, G. (I97I). Recent developments in the chemistry, biochemistry, geochemistry and posttetrad ontogeny of sporopollenins derived from pollen and spore exines. In Pollen: Development and Physiology, pp. 99-I I4. Edited by J. Heslop-Harrison. London: Butterworths.

Bu'Lock, J. D. (1961). Intermediary metabolism and antibiotic synthesis. Advances in Applied Microbiology 3, 293-342.

Bu'Lock, J. D. (1967). Essays in Biosynthesis and Microbial Development. New York: John Wiley.

BurnetT, J. H. (1965). Functions of carotenoids other than in photosynthesis. In Chemistry and Biochemistry of Plant Pigments, pp. 381-403. Edited by T. W. Goodwin. London: Academic Press.

BusH, I. ( 1963). General applicability of the channels ratio method of measuring liquid scintillation counting efficiencies. Analytical Chemistry 35, $1024-1029$.

Buyske, D. A., Kelly, R., Florini, J., Gordon, S. \& Peets, E. (196I). Determination of T and $\mathrm{C}^{14}$ in biological samples by rapid combustion techniques. Atomlight, no. 20, I-6.

VAN DEN ENDE, H. (1968). Relationship between sexuality and carotene synthesis in Blakeslea trispora. Journal of Bacteriology 96, I 298-1 303.

Gooday, G. W. (I968a). Hormonal control of sexual reproduction in Mucor mucedo. New Phytologist 67, $8 \mathrm{I} 5-82 \mathrm{I}$.

Gooday, G. W. (I968b). The extraction of a sexual hormone from the mycelium of Mucor mucedo. Phytochemistry 7, 2103-2105.

HAWKER, L. E. \& BECKETt, A. (197I). Fine structure and development of the zygospore of Rhizopus sexualis (Smith) Callen. Philosophical Transactions of the Royal Society of London 263, 7I-I 00.

Hawker, L. E. \& Gooday, M. A. (I968). Development of the zygospore wall in Rhizopus sexualis (Smith) Callen. Journal of General Microbiology 54, 13-20.

Hesseltine, C. W. (196I). Carotenoids in the fungi Mucorales. United States Department of Agriculture Technical Bulletin, no. $1245,1-33$.

HockIng, D. (1963). $\beta$-Carotene and sexuality in the Mucoraceae. Nature, London r97, 404.

Hocking, D. (1965). Demonstration of $\beta$-carotene in gametangia of Phycomyces blakesleeanus Burgeff. Nature, London 206, 846.

Ling-Young, M. (1930). Études biologiques des phénomèns de la sexualité chez les Mucorinées. Revue Générale de Botanique 42, 681-704; 43, 30-43.

Petracek, F. J. \& Zechmeister, L. (1956). The hydrolytic cleavage products of boron trifluoride complexes of $\beta$-carotene, some dehydrogenated carotenes and anhydro-vitamin A. Journal of the American Chemical Society 78, 3188-3193.

SHAw, G. (1970). Sporopollenin. In Phytochemical Phylogeny, pp. 3 I-58. Edited by J. B. Harborne. London: Academic Press.

Shaw, G. (1971). The chemistry of sporopollenin. In Sporopollenin, pp. 305-350. Edited by J. Brooks, P. R. Grant, M. D. Muir, P. van Gijzel and G. Shaw. London: Academic Press.

Sutter, R. P. \& Rafelson, M. E. (I968). Separation of $\beta$-factor synthesis from stimulated $\beta$-carotene synthesis in mated cultures of Blakeslea trispora. Journal of Bacteriology 95, 426-432.

Thomas, D. M. \& Goodwin, T. W. (1967). Studies on carotenogenesis in Blakeslea trispora. I. General observations on synthesis in mated and unmated strains. Phytochemistry 6, 355-360. 